\title{
A proteomics approach to characterizing human submandibular gland cell lines by fluorescent two-dimensional differential in-gel electrophoresis
}

\author{
ATSUSHI KASAMATSU ${ }^{1}$, KATSUHIRO UZAWA ${ }^{1,3}$, DAI NAKASHIMA ${ }^{1}$, \\ YUKINAO KOUZU ${ }^{1}$, YOSUKE ENDO ${ }^{1}$, HIROFUMI KOIKE ${ }^{1}$, HIDETAKA YOKOE $^{3}$, \\ KOJI HARADA ${ }^{4}$, MITSUNOBU SATO ${ }^{4}$ and HIDEKI TANZAWA ${ }^{1-3}$
}

\begin{abstract}
${ }^{1}$ Department of Clinical Molecular Biology, ${ }^{2}$ Center of Excellence (COE) Program in the 21st Century, Graduate School of Medicine, Chiba University; ${ }^{3}$ Division of Oral Surgery, Chiba University Hospital, 1-8-1 Inohana, Chuo-ku, Chiba 260-8670; ${ }^{4}$ The Second Department of Oral and Maxillofacial Surgery,

Faculty of Dentistry, Tokushima University, 3-18-15 Kuramoto-cho, Tokushima 770-8504, Japan
\end{abstract}

Received August 29, 2005; Accepted October 3, 2005

\begin{abstract}
The human salivary glands have a variety of histologic features such as intercalated duct cells, myoepithelial cells and acinar cells. A neoplastic human salivary intercalated duct cell line (HSG) and its derivatives, HSG with a myoepithelial cell phenotype (HSG-AZA1) and HSG with an acinar cell phenotype (HSG-AZA3) induced by 5aza-2'-dC treatment of HSG cells, have been reported. To identify characterization of intercalated duct cells, myoepithelial cells and acinar cells in the salivary gland, we selected HSG, HSG-AZA1 and HSG-AZA3 cell lines to perform two-dimensional electrophoresis analysis. We used a fluorescent two-dimensional differential in-gel electrophoresis (2-D-DIGE) for comparative proteomics, which improved the reproducibility and reliability of differential protein expression analysis between the samples. Furthermore, matrix-assisted laser desorption/ionization time-of-flight (MALDI-TOF) peptide mass fingerprinting (PMF) was used to identify the proteins. These methods were combined to approach the protein profiles associated with characterization between HSG, HSG-AZA1 and HSG-AZA3 cells. Using these strategies, we identified seven HSG associated proteins, such as actin- $\beta$, hydrocephalus inducing protein, L-plastin, KIAA0657 protein, septin 6 isoform A, lamin A/C isoform 2 and superoxide dismutase 2, three HSG-AZA1 associated proteins such as ubiquitin carboxyl-terminal esterase L1, myosin light chain 2 and muscle creatine kinase, and two HSG-AZA3 associated proteins, microtubule-associated
\end{abstract}

Correspondence to: Dr Katsuhiro Uzawa, Chiba University, 1-8-1 Inohana, Chuo-ku, Chiba 260-8670, Japan

E-mail: uzawak@faculty.chiba-u.jp

Key words: HSG, HSG-AZA1, HSG-AZA3, submandibular gland, fluorescent two-dimensional differential in-gel electrophoresis protein 6 and Annexin A3. These results suggest that the proteins are associated with characterization of the salivary gland.

\section{Introduction}

The salivary glands have diverse cell types. Terminal end pieces, associated with salivary secretions, are composed of acinar cells and myoepithelial cells, and their central lumina communicate directly with the intercalated duct $(1,2)$.

The human salivary cell line, HSG, which is derived from the submandibular gland, has features of the intercalated duct. When HSG cells were treated with 5-aza-2'-dC, the cells underwent DNA hypomethylation. Therefore, HSG-AZA1 cells (myoepithelial cell phenotype) and the HSG-AZA3 cells (acinar cell phenotype) were isolated from the HSG cells. Myosin was the specific marker of HSG-AZA1 cells, and amylase of the HSG-AZA3 cells (3). Previous studies reported that HSG, HSG-AZA1, and HSG-AZA3 cells produced adenocarcinoma, myoepithelioma, and acinar cell carcinoma, respectively, in nude mice that had undergone transplantation with those cells (3-5) suggesting that cytodifferentiation therapy has the potential to treat salivary gland tumors.

Two-dimensional (2-D) gel electrophoresis is the principal step of proteomics and widely used in comparative studies of protein expression levels of certain samples. 2-D gel electrophoresis is a well-established technique for the simultaneous separation and display of hundreds to thousands of proteins (6). The method separates proteins into two dimensions according to their isoelectric point and molecular size. Traditionally, identification of significant differences between two or more proteomes by 2-D gel electrophoresis required the running and analysis of many gels. However, the reproducibility of comparing proteomes by this method is hindered by technical variations in sample preparation and gel-running conditions. Fluorescent 2-D differential in-gel electrophoresis (2-D-DIGE), described recently by several research groups 
(7-11), allows multiplex analysis of three sample proteomes on the same gel. The protein extracts being compared are covalently labeled with different fluorescent CyDyes, such as $\mathrm{Cy} 2, \mathrm{Cy} 3$, and Cy5. Fluorescent imaging of the gels at the wavelengths specific for each CyDye generates images that can be overlaid directly by the DeCyder software to identify any differentially expressed proteins among the samples.

In the present study, to investigate specific markers of intercalated duct cells, myoepithelial cells, and acinar cells, we selected three cell lines (HSG, HSG-AZA1, and HSGAZA3), and performed proteomic analysis using 2-D-DIGE and matrix-assisted laser desorption/ionization time-of-flight (MALDI-TOF) mass spectrometry.

\section{Materials and methods}

Sample preparation. The three cell types (HSG, HSG-AZA1 and HSG-AZA3) were transplanted into nude mice to produce tumor tissue (3). The expression of specific markers, such as carcinoembryonic antigen (CEA), myosin, and amylase, of these tumor tissues were confirmed as described previously $(3,12)$. We then selected the tumor tissues to be used in this study. The tumor tissues were washed in cold phosphatebuffered saline (PBS). Samples were crushed by liquid nitrogen and resuspended in lysis buffer (7 M urea, $2 \mathrm{M}$ thiourea, $4 \% \mathrm{w} / \mathrm{v}$ CHAPS, $10 \mathrm{mM}$ Tris $\mathrm{pH} \mathrm{8.0).} \mathrm{Insoluble}$ materials were removed by centrifugation at 13,000 rpm for $20 \mathrm{~min}$ at $10^{\circ} \mathrm{C}$. The protein concentration was determined using a commercial Bradford reagent (Bio-Rad, Richmond, CA). The model proteins were dissolved in lysis buffer to provide stock solutions with final concentrations of $1 \mathrm{mg} / \mathrm{ml}$ that were used to prepare the experimental samples.

Sample labeling. The pooled standard sample was prepared by pooling protein from each of the samples before labeling. A 1-mM stock of each dye was diluted 1:5 with anhydrous dimethyl formamide just before the labeling reaction. Approximately $50 \mu \mathrm{g}$ of each protein extract (in $4 \mu \mathrm{l}$ ) was mixed with $1 \mu 1$ of CyDye Cy2, Cy3, or Cy5 (0.2 mM) (Amersham Biosciences, Buckinghamshire, UK), vortexed, and incubated on ice for $30 \mathrm{~min}$ in the dark as described by Skynner et al (11). The reaction was quenched by the addition of $10 \mathrm{mM}$ lysine.

2-D gel electrophoresis. Before isoelectric focusing (IEF), pooled Cy2-labeled extracts were combined with the Cy3labeled sample extracts and Cy5-labeled extracts according to the experimental design (Table I). The combined labeled samples were added to an equal volume of $2 \mathrm{X}$ the sample buffer (7 M urea, $2 \mathrm{M}$ thiourea, 4\% w/v CHAPS, 2\% v/v Pharmalytes $\mathrm{pH} 3-10$ ), vortexed, and incubated on ice for another $10 \mathrm{~min}$ in the dark. In addition, the volume of the combined labeled samples was adjusted to $450 \mu 1$ with a standard rehydration buffer (7 M urea, $2 \mathrm{M}$ thiourea, 4\% w/v CHAPS, $1 \%$ v/v Pharmalytes pH 3-10). Immobiline DryStrips (pH 3-10 NL, $24 \mathrm{~cm}$ ) (Amersham Biosciences) were rehydrated overnight.

IEF was carried out at $500 \mathrm{~V}$ for $500 \mathrm{~V} / \mathrm{h}, 1,000 \mathrm{~V}$ for $1,000 \mathrm{~V} / \mathrm{h}$, and $8,000 \mathrm{~V}$ for $64,000 \mathrm{~V} / \mathrm{h}$ at $20^{\circ} \mathrm{C}$ and a maximum current setting of $50 \mu \mathrm{A} /$ strip in an IPGphor II IEF unit
Table I. Experimental design for 2-D-DIGE.

\begin{tabular}{llll}
\hline Gel & \multicolumn{1}{c}{ Cy2 } & \multicolumn{1}{c}{ Cy3 } & \multicolumn{1}{c}{ Cy5 } \\
\hline 1 & Pooled standard & HSG & HSG-AZA1 \\
2 & Pooled standard & HSG-AZA1 & HSG \\
3 & Pooled standard & HSG & HSG-AZA3 \\
4 & Pooled standard & HSG-AZA1 & HSG-AZA3 \\
5 & Pooled standard & HSG-AZA3 & HSG \\
\hline
\end{tabular}

Approximately $50 \mathrm{mg}$ of each extract and the pooled standard were labeled with the indicated CyDye and mixed. Electrophoresis analysis was then performed on 2-D gel as indicated.

(Amersham Biosciences). Before sodium deodecyl sulfatepolyacrylamide gel electrophoresis (SDS-PAGE), each strip was equilibrated with $10 \mathrm{ml}$ equilibration buffer A (6 M urea, $100 \mathrm{mM}$ Tris- $\mathrm{HCl} \mathrm{pH} 8.0,30 \%$ v/v glycerol, $2 \%$ w/v SDS, $0.5 \% \mathrm{w} / \mathrm{v}$ DTT) for $15 \mathrm{~min}$, followed by $10 \mathrm{ml}$ equilibration buffer B (6 M urea, $100 \mathrm{mM}$ Tris- $\mathrm{HCl}$ pH 8.0, 30\% v/v glycerol, $2 \% \mathrm{w} / \mathrm{v}$ SDS, $4.5 \% \mathrm{w} / \mathrm{v}$ iodoacetamide) for another $15 \mathrm{~min}$.

The strips then were loaded and run on $12 \%$ acrylamide isocratic Laemmli gels (13) using the Ettan DALT six apparatus (Amersham Biosciences). Gels were run at $2.5 \mathrm{~W} /$ gel for $30 \mathrm{~min}$ and then increased to $100 \mathrm{~W}$ after the proteins migrated into the resolving gel. The gel electrophoresis run was terminated once the bromophenol blue dye (Amersham Biosciences) migrated off the bottom of the gel.

Image acquisition and analysis. Labeled proteins were visualized using the Typhoon 9400 Imager (Amersham Biosciences). The Cy2 images were scanned using a 488-nm laser and a 520-nm emission filter, band pass (BP) 40. Cy3 images were scanned using a 532-nm laser and a 580-nm emission filter BP30. Cy5 images were scanned using a 633-nm laser and a 670-nm emission filter BP30.

On individual gels, the Cy2-labeled images (pooled standard) were compared with either the $\mathrm{Cy} 3$ or the Cy5 images from the individual HSG, HSG-AZA1, and HSGAZA3 cell lines using the DeCyder-differential in-gel analysis software (Amersham Biosciences). The estimated number of spots for each co-detection procedure was set to 3,000. Gelto-gel matching of the standard spot maps from each gel, followed by statistical analysis of protein abundance changes between samples, was then performed using the DeCyderbiological variation analysis software module (Amersham Biosciences). The statistical significance of each expression level was calculated using the Student's t-test on the logged ratios. This analysis is equivalent to doing a paired t-test and has increased power because it takes into account the pairing of samples within gels. Protein spot expression levels, which showed a statistically significant $(\mathrm{P}<0.001)$ increase or decrease on every gel used in the study, were accepted as being differentially expressed between the extracts under comparison. The 2-D-DIGE workflow is described in Fig. 1. 


\section{Cy2-labeling}

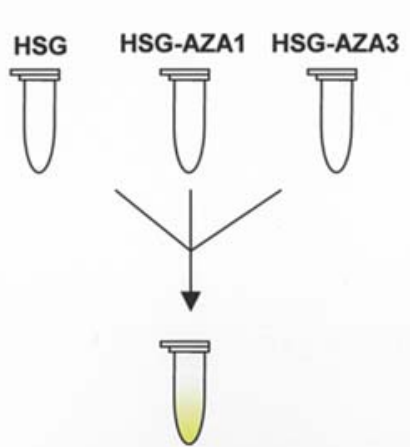

Pooled Standard
Cy3-labeling
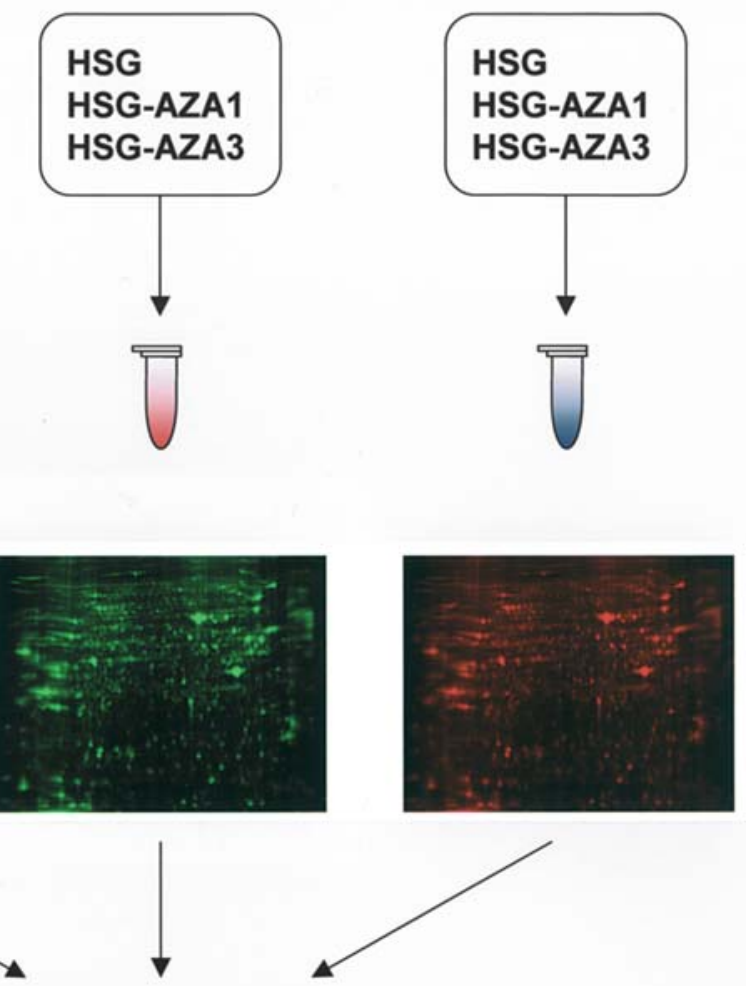

\section{Cy5-labeling}

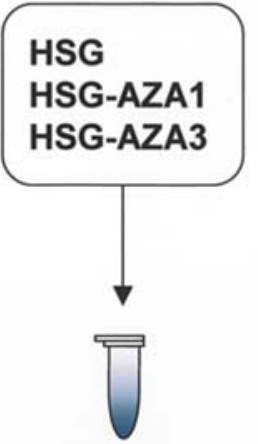

HSG

HSG-AZA1

HSG-AZA3

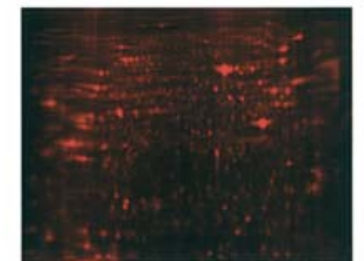

Fluorescent 2-D-DIGE
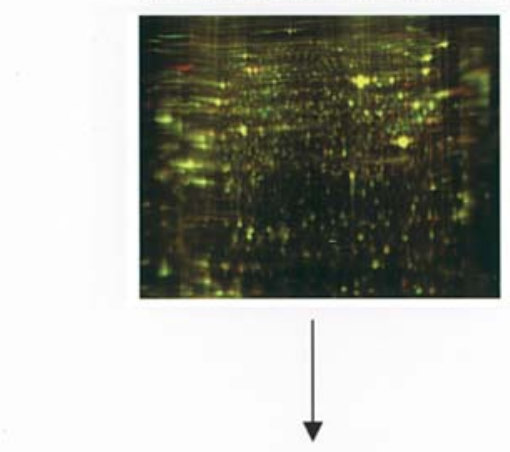

Statistical and quantitative analyses

Figure 1. 2-D-DIGE workflow. The pooled standard was labeled with Cy2. Experimental proteins, HSG, HSG-AZA1, and HSG-AZA3, were labeled with Cy3 and Cy5, respectively, according to Table I. The pooled standard and experimental proteins were then mixed for electrophoresis on the same 2-D-DIGE gel. Statistical and quantitative analyses were performed using DeCyder software.

MALDI-TOF peptide mass fingerprinting $(P M F)$ analysis and database search. Separate preparative gels electrophoresed with individual HSG, HSG-AZA1, and HSG-AZA3 cell lines were fixed and then stained with SYPRO Ruby (Molecular Probes, Inc., Eugene, OR). The resulting fluorescent images were matched to CyDye images using DeCyder software. A spot-picking list was generated from DeCyder and exported to an automated spot-handling system (Ettan Spot Picker, Amersham Bioscience). The gel spots were excised as circular plugs $2 \mathrm{~mm}$ in diameter and delivered into 96-well microtiter plates.

In-gel digestion was performed with an enzyme solution containing $50 \mathrm{mM} \mathrm{NH}_{4} \mathrm{HCO}_{3}, 5 \mathrm{mM} \mathrm{CaCl}_{2}$, and $12.5 \mathrm{ng} / \mu \mathrm{l}$ trypsin. Aliquots of the purified samples were spotted on matrix crystals of $\alpha$-cyano-4-hydroxyl-cinnamic acid on a stainless-steel target and air dried. Mass determinations were performed on the AXIMA-CFR Mass Spectrometer (Shimadzu Co. Ltd., Kyoto, Japan). The proteins were identified by the PMF method, using Mascot Search on the Web (http://www. matrixscience.com/cgi/index.pl?page=../home.html) (Matrix Science, Ltd., London, UK).

Immunohistochemistry. To confirm the results of PMF analysis, immunohistochemistry was carried out. Briefly, the $4 \mu \mathrm{m}$ paraffin-embedded specimen of normal submandibular glands were deparaffinized and hydrated. The slides were treated with endogenous peroxidase in $0.3 \% \mathrm{H}_{2} \mathrm{O}_{2}$ for $30 \mathrm{~min}$, and the sections were blocked for $2 \mathrm{~h}$ at room temperature 


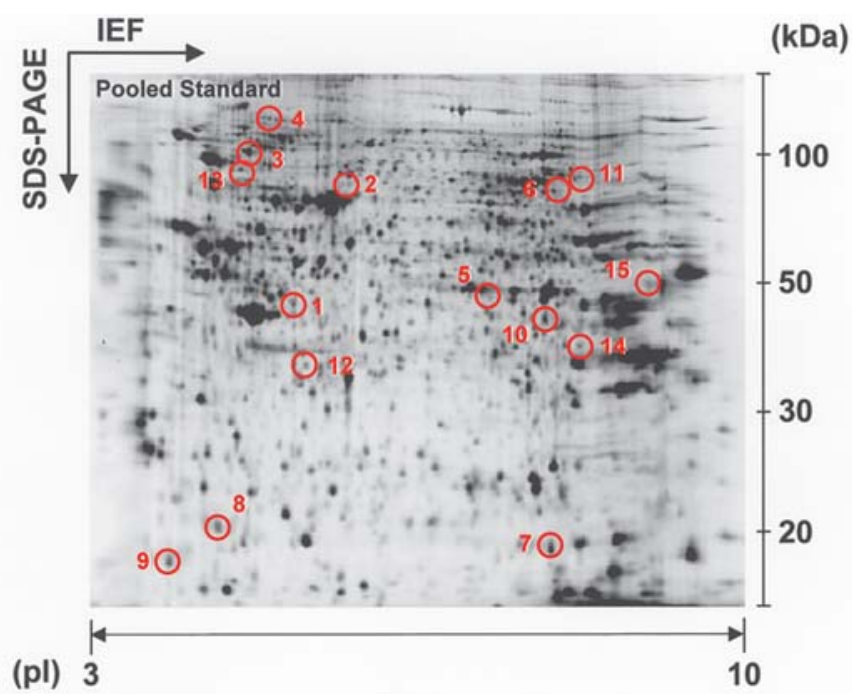

Figure 2. Typical 2-D-DIGE gel images of the pooled standard. The protein lysates were labeled with either Cy3 or Cy5 and subjected to 2-D-DIGE using pH 3-10 Immobiline DryStrips. HSG-associated proteins are represented by spots 1-7; HSG-AZA1-associated proteins are represented by spots 8-10; HSG-AZA3-associated proteins are represented by spots 11 and 12 .

with $1.5 \%$ blocking serum (Santa Cruz Biotechnology, Santa Cruz, CA) in PBS before reacting with anti-human myosin light chain 2 (MLC2) polyclonal antibody (Santa Cruz Biotechnology) at a dilution of 1:100. They then were incubated with primary antibody and non-immune control antibody for $3 \mathrm{~h}$ at room temperature in a moist chamber. Thereafter, samples were incubated with biotinylated anti-goat
IgG and peroxidase-conjugated streptavidin. The peroxdase reaction was performed using a 3,3'-diaminobenzidine tetrahydochloride (Dako Japan Inc., Kyoto, Japan). Finally, the slides were counterstained with hematoxylin, dehydrated in graded ethanol, cleaned in xylene, and mounted.

\section{Results}

Proteomic analysis of differentially expressed proteins among HSG, HSG-AZA1, and HSG-AZA3 cells by 2-D-DIGE. To identify the different factors among the HSG, HSG-AZA1, and HSG-AZA3 cells, we used the 2-D-DIGE technology to monitor changes in the abundance of proteins. The samples were run in triplicate to obtain statistical significance for protein differences. An average of 2,500 spots was detected across all five gels by the DeCyder software (Fig. 2). We found seven protein spots in the HSG cells that were upregulated $>3$-fold, and three protein spots that were downregulated $>3$-fold compared with the HSG-AZA1 cells (Tables II and III) $(\mathrm{P}<0.001)$. We also identified seven spots as up-regulated and five spots as down-regulated proteins compared with the HSG-AZA3 cells (Tables II and III) $(\mathrm{P}<0.001)$. Of the up-regulated proteins in the HSG cells, we identified seven proteins that were expressed in common with the HSG-AZA1 and HSG-AZA3 cells. Moreover, 5 spots were differentially expressed $>3$-fold between the HSG-AZA1 and HSG-AZA3 cells (Table IV) $(\mathrm{P}<0.001)$.

MALDI-TOF PMF analysis. Based on the comparative analysis of protein expression patterns among the HSG, HSG-AZA1, and HSG-AZA3 cells, the 15 differentially

Table II. Up-regulated proteins in HSG compared with HSG-AZA1 or HSG-AZA3.

\begin{tabular}{|c|c|c|c|c|}
\hline Accession no. & Protein & Theoretical pl/Mw (kDa) & t-test & Average ratio \\
\hline \multicolumn{5}{|c|}{ Compared with HSG-AZA1 } \\
\hline Hs. 426930 & $\mathrm{ACTB}^{\mathrm{a}}$ & $5.6 / 40.5$ & 0.00036 & -12.68 \\
\hline Hs. 47115 & HYDIN protein ${ }^{\mathrm{a}}$ & $5.7 / 80.7$ & $7.50 \mathrm{e}-07$ & -7.1 \\
\hline Hs. 381099 & L-plastin ${ }^{\mathrm{a}}$ & $5.2 / 70.8$ & $2.30 \mathrm{e}-08$ & -5.89 \\
\hline Hs. 6654 & KIAA0657 protein ${ }^{\mathrm{a}}$ & $5.3 / 138.2$ & $6.60 \mathrm{e}-06$ & -4.67 \\
\hline Hs. 90998 & Septin 6 isoform $A^{a}$ & $6.4 / 49.2$ & 0.00011 & -3.16 \\
\hline Hs. 436441 & Lamin $\mathrm{A} / \mathrm{C}$ isoform $2^{\mathrm{a}}$ & $6.4 / 65.2$ & $2.70 \mathrm{e}-06$ & -3.12 \\
\hline Hs. 384944 & $\mathrm{SOD} 2^{\mathrm{a}}$ & $6.9 / 22.2$ & $9.50 \mathrm{e}-06$ & -3.04 \\
\hline \multicolumn{5}{|c|}{ Compared with HSG-AZA3 } \\
\hline Hs. 426930 & $\mathrm{ACTB}^{\mathrm{a}}$ & $5.6 / 40.5$ & 0.0008 & -8.33 \\
\hline Hs. 381099 & L-plastin ${ }^{\mathrm{a}}$ & $5.2 / 70.8$ & $3.00 \mathrm{e}-07$ & -5.37 \\
\hline Hs. 6654 & KIAA0657 protein ${ }^{a}$ & $5.3 / 138.2$ & 0.0001 & -3.78 \\
\hline Hs. 436441 & Lamin $\mathrm{A} / \mathrm{C}$ isoform $2^{\mathrm{a}}$ & $6.4 / 65.2$ & $6.60 \mathrm{e}-06$ & -3.61 \\
\hline Hs. 90998 & Septin 6 isoform $\mathrm{A}^{\mathrm{a}}$ & $6.4 / 49.2$ & 0.00011 & -3.32 \\
\hline Hs. 47115 & HYDIN protein ${ }^{\mathrm{a}}$ & $5.7 / 80.7$ & $4.00 \mathrm{e}-07$ & -3.26 \\
\hline Hs. 384944 & $\mathrm{SOD} 2^{\mathrm{a}}$ & $6.9 / 22.2$ & $9.60 \mathrm{e}-08$ & -3.02 \\
\hline
\end{tabular}

${ }^{\mathrm{a}} \mathrm{HSG}$-associated protein. 
Table III. Down-regulated proteins in HSG compared with HSG-AZA1 or HSG-AZA3.

\begin{tabular}{|c|c|c|c|c|}
\hline Accession no. & Protein & Theoretical pl/Mw (kDa) & t-test & Average ratio \\
\hline \multicolumn{5}{|c|}{ Compared with HSG-AZA1 } \\
\hline Hs. 76118 & $\mathrm{UCHL}^{\mathrm{a}}$ & $5.3 / 25.2$ & 0.00035 & 12.06 \\
\hline Hs. 50889 & $\mathrm{MLC}^{\mathrm{a}}$ & $4.9 / 19.1$ & 0.00049 & 11.23 \\
\hline Hs. 334347 & $\mathrm{MCK}^{\mathrm{a}}$ & $6.8 / 43.3$ & $6.90 \mathrm{e}-05$ & 5.98 \\
\hline \multicolumn{5}{|c|}{ Compared with HSG-AZA3 } \\
\hline Hs. 239444 & MAP6 $^{\mathrm{b}}$ & $9.3 / 77.1$ & $8.00 \mathrm{e}-7$ & 6.67 \\
\hline Hs. 442733 & Annexin $\mathrm{A} 3^{\mathrm{b}}$ & $5.6 / 36.5$ & 0.0001 & 3.29 \\
\hline Hs. 1742 & IQGAP1 & $5.6 / 108.0$ & $6.40 \mathrm{e}-05$ & 3.22 \\
\hline Hs. 286049 & PSAT1 & $7.6 / 40.8$ & $3.40 \mathrm{e}-05$ & 3.18 \\
\hline Hs. 58324 & ADAMTS5 & $9.2 / 58.8$ & 0.00056 & 3.03 \\
\hline
\end{tabular}

IQGAP1, IQ motif containing GTPase activating protein 1; PSAT1, phosphoserine aminotransferase isoform 1; ADAMTS5, a disintegrin-like and metalloprotease (reprolysin type) with thrombospondin type 1 motif, 5 (aggrecanase-2). ${ }^{\text {HSSG-AZA1-associated protein. }{ }^{\mathrm{b}} \mathrm{HSG}-\mathrm{AZA} 3-}$ associated protein.

Table IV. Proteins differentially expressed in HSG-AZA1 and HSG-AZA3.

\begin{tabular}{|c|c|c|c|c|}
\hline Accession no. & Protein & Theoretical pl/Mw (kDa) & t-test & Average ratio \\
\hline \multicolumn{5}{|c|}{ Highly expressed in HSG-AZA1 } \\
\hline Hs. 76118 & $\mathrm{UCHL}^{\mathrm{a}}{ }^{\mathrm{a}}$ & $5.3 / 25.2$ & 0.00026 & 11.57 \\
\hline Hs. 50889 & $\mathrm{MLC}^{\mathrm{a}}$ & $4.9 / 19.1$ & 0.00032 & 8.5 \\
\hline Hs. 334347 & $\mathrm{MCK}^{\mathrm{a}}$ & $6.8 / 43.3$ & 0.00024 & 6.55 \\
\hline \multicolumn{5}{|c|}{ Highly expressed in HSG-AZA3 } \\
\hline Hs. 239444 & MAP6 $^{\mathrm{b}}$ & $9.3 / 77.1$ & $1.20 \mathrm{e}-05$ & -7.19 \\
\hline Hs. 442733 & Annexin $A 3^{b}$ & $5.6 / 36.5$ & 0.0001 & -6.25 \\
\hline
\end{tabular}

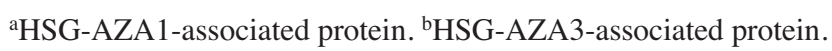

expressed proteins were selected for further analysis. These spots were robotically excised from the gels for MALDITOF PMF analysis. All were specifically digested by trypsin and got peptide masses maps from the PMF analysis. Fifteen known proteins were extracted from the analysis. Fig. 3 shows representative results of PMF analysis.

Protein identification by MALDI-TOF PMF analysis. We identified seven $\mathrm{HSG}$-associated proteins, i.e., actin- $\beta$ (ACTB), hydrocephalus-inducing protein (HYDIN protein), L-plastin, KIAA0657 protein, septin 6 isoform A, lamin A/C isoform 2, and superoxide dismutase 2 (SOD2); three HSGAZA1 associated proteins, i.e., ubiquitin carboxyl-terminal esterase L1 (UCHL1), myosin light chain 2 (MLC2), and muscle creatine kinase (MCK); and two HSG-AZA3-associated proteins, microtubule-associated protein 6 (MAP6) and Annexin A3 (Tables II-V). Of these proteins, the functions are known for eight and unknown for three. In addition, these proteins were functionally categorized, based on the known or inferred biologic functions, into structural protein, structural protein activity, actin-binding protein, guanosine triphosphatebinding protein, SOD activity, hydrase activity, and creatine kinase activity.

3-D images and immunohistochemistry of identified protein. Typical results from the DeCyder software for MLC2 protein spots are shown in Fig. 4A. In the 2-D and 3-D images of the HSG-AZA1 cells, we detected overexpression of this protein. We did not detect these protein spots in the HSG and HSGAZA3 cells. In this study, the differences in protein expression were detected more easily by the DeCyder 3-D simulations of the spots.

To investigate the distribution of MLC2 protein expression in vivo, we performed immunohistochemical staining of the protein in the submandibular gland. Fig. 4B shows representative staining results of MLC2. Myoepithelial cells lining the acini periphery were positive for MLC2 in the normal submandibular gland. 
A

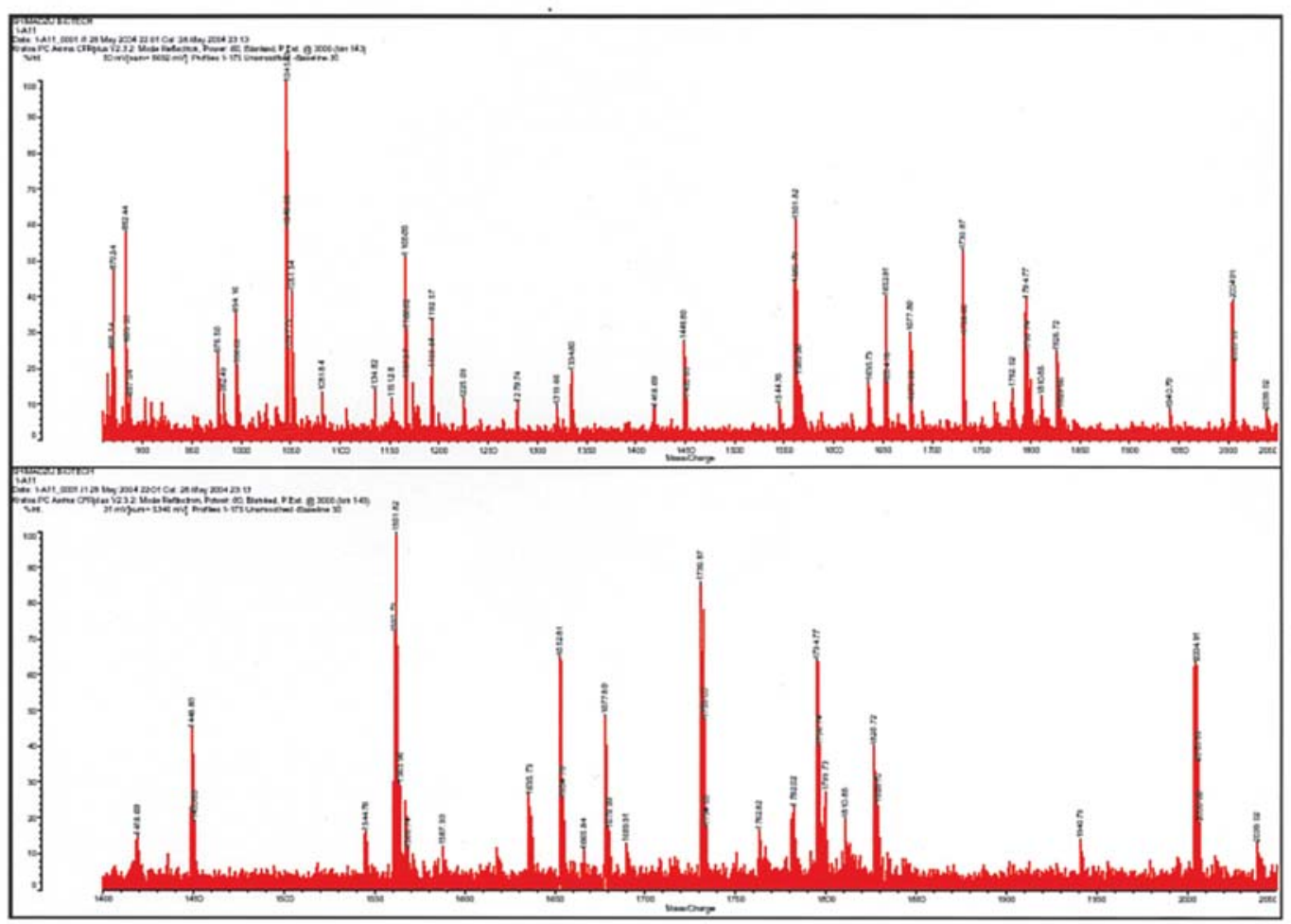

B

\section{MAPKRAKRRT VAEGGSSSVF SMFDQTQIQE FKEAFTVIDQ NRDGIIDKED 51 LRDTFAAMGR LNVKNEELDA MMKEASGPIN FTVFLTMFGE KLKGADPEDV 101 ITGAFKVLDP EGKGTIKKKF LEELLTTQCD RFSQEEIKNM WAAFPPDVGG 151 NVDYKNICYV ITHGDAKDQE}

Figure 3. MALDI-TOF mass spectrometric analysis of MLC2, which was expressed more frequently in the HSG-AZA1 cells. (A) Results of MALDI-TOF mass spectrometric analysis. (B) Amino acid sequences analyzed by PMF analysis and underlined on the full-length sequence of the protein.

A
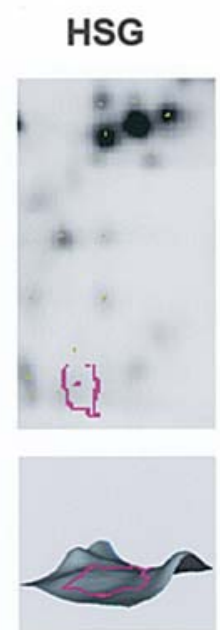

HSG-AZA1
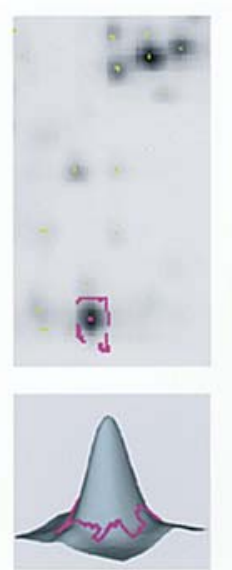

B

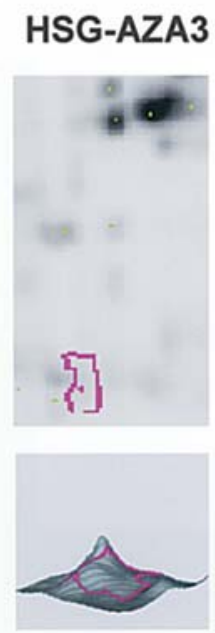

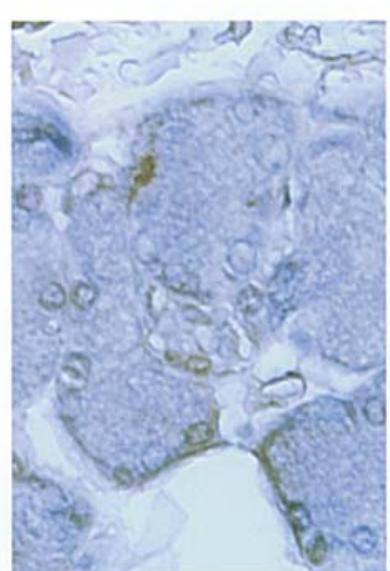

Figure 4. Typical results of protein expression in the HSG, HSG-AZA1, and HSG-AZA3 cells using DeCyder software and immunohistochemical staining of MLC2 protein. (A) The MLC2 protein expression levels in the HSG-AZA1 cells are significantly $(\mathrm{P}<0.001)$ higher than that in the HSG and HSG-AZA3 cells. (B) MLC2 is seen in the myoepithelial cells. Original magnification, $\mathrm{x} 400$. 
Table V. Associated proteins in HSG, HSG-AZA1, and HSGAZA3 cell lines.

\begin{tabular}{cll}
\hline Spot no. & Accession no. & \multicolumn{1}{c}{ Protein } \\
\hline $\begin{array}{l}\text { HSG-associated } \\
\text { proteins }\end{array}$ & & \\
1 & & \\
2 & Hs. 426930 & ACTB \\
3 & Hs. 47115 & HYDIN protein \\
4 & Hs. 381099 & L-plastin \\
5 & Hs. 6654 & KIAA0657 protein \\
6 & Hs. 90998 & Septin 6 isoform A \\
7 & Hs. 436441 & Lamin A/C isoform 2 \\
HSG-AZA1- & Hs. 384944 & SOD2 \\
associated proteins & & \\
8 & Hs. 76118 & UCHL1 \\
9 & Hs. 50889 & MLC2 \\
10 & Hs. 334347 & MCK \\
HSG-AZA3- & & \\
associated proteins & & \\
11 & Hs. 239444 & MAP6 \\
12 & Hs. 442733 & Annexin A3 \\
\hline
\end{tabular}

\section{Discussion}

Because the functional molecules in the cells are protein, proteome analysis based on 2-D gel electrophoresis has several advantages over cDNA/oligonucleotide microarray systems for clinical use. First, the system measures primarily high-abundance proteins, which are ideal specific biomarkers because they can be measured and targeted easily. mRNA levels are not directly associated with the amounts of functional proteins (14). Second, using proteomics, we can analyze the post-translational modifications that are essential for protein formation and function. For many proteins, post-translational modifications are important for their functions, and they can be analyzed only by the methods used in proteomics $(15,16)$.

The present study showed that 2-D-DIGE is a robust method for identifying statistically significant changes in protein abundance among three samples. The technique provides reliable identification of proteomic differences among the samples, because multiple samples can be analyzed on a single gel and an internal standard can be included for accurate matching across gels (17). The use of an internal standard helps to minimize false positives and negatives because it provides a separate control for each individual protein spot on all gels in the analysis (17). It is possible that the CyDyes may show some artifactual preferential labeling of some proteins, although none was detected in this study.

To investigate the proteins associated with cytodifferentiation of myoepithelial cells or acinar cells from parental cells (intercalated duct cells), we performed 2-D-DIGE analysis. We identified seven HSG-associated proteins, three HSG-AZA1-associated proteins, and two HSG-AZA3associated proteins.

Because HSG-AZA1 and HSG-AZA3 cells were affected by 5 -aza-2'-dC, the forms differed from the HSG cells. Therefore, expressions of structural proteins recognized the differences among the HSG, HSG-AZA1, and HSG-AZA3 cells. Of the seven HSG-associated proteins, we found three structural proteins, such as ACTB, L-plastin, and lamin A/C. ACTB is a structural constituent of cytoskeleton (18); Lplastin is a member of a family of actin-binding proteins (19); lamin $\mathrm{A} / \mathrm{C}$ is related to structural molecular activity 20 . The expression of lamin $\mathrm{A} / \mathrm{C}$, a nuclear membrane protein, lacks several types of undifferentiated cells (20). Since HSG cells can differentiate into myoepithelial and acinar cells, it was thought that lamin $\mathrm{A} / \mathrm{C}$ was overexpressed in HSG cells compared with HSG-AZA1 and HSG-AZA3 cells.

Of the HSG-AZA1-associated proteins, we found MLC2 and MCK. These proteins are related to muscle differentiation (21) and were reported to be specific markers of muscle (21). The marker of the HSG-AZA1 cells, myosin, was reported previously $(3,22)$. In the present study, we identified overexpression of MLC2 and MCK in the HSG-AZA1 cells. Therefore, these results suggested that MLC2 and MCK are specific markers of both the muscle cells and the myoepithelial cells.

Of the HSG-AZA3-associated proteins, MAP6 is a calmodulin-binding and calmodulin-regulated protein that is involved in microtubule stabilization (23). The MAP family was reported to be associated with pancreas acinar cells (24). This observation together with our results suggests that MAP6 may play a role in the acinar cells of the salivary gland.

Several studies have shown that CEA, myosin, and amylase were expressed in salivary gland-derived cell lines such as HSG, HSG-AZA1, and HSG-AZA3 $(3,12,25-27)$. On the other hand, we could not detect spots of the specific markers for HSG and HSG-AZA3 cells lines. The proteins showing up- or down-regulation at $>3$-fold were selected for PMF analysis. One possible explanation for this discrepancy is that expression level of specific markers was $<3$-fold upregulation.

In conclusion, our 2-D-DIGE technology combined with MALDI-TOF PMF analysis identified candidate specific markers among the myoepithelial phenotype (HSG-AZA1), the acinar cell phenotype (HSG-AZA3), and their parental cells derived from the intercalated duct (HSG). Although salivary gland tumors consist of various types of cells, the proteins identified in this study could be useful biomarkers of salivary gland diseases.

\section{References}

1. Ten Cate AR: Oral Histology. 5th edition. St. Louis, MO, pp315-344, 1998.

2. Hayashi Y, Yanagawa T, Azuma M, Yura Y, Yoshida H and Sato M: Induction of cells with a myoepithelial cell phenotype by treatment with dibutyryl cyclic AMP in human salivary adenocarcinoma cells grown in athymic nude mice. Virchows Arch 50: 1-11, 1985.

3. Sato M, Azuma M, Hayashi Y, Yoshida H, Yanagawa T and Yura Y: 5-Azacytideine induction of stable myoepithelial and acinar cells from a human salivary intercalated duct cell clone. Cancer Res 47: 4453-4459, 1987. 
4. Shirasuna K, Sato M and Miyazaki T: A neoplastic epithelial duct cell line established from an irradiated human salivary gland. Cancer 48: 745-752, 1981.

5. Sato M, Hayashi Y, Yoshida H, Yanagawa T, Yura Y and Nitta T: Search for specific markers of neoplastic epithelial duct and myoepithelial cell lines established from human salivary gland and characterization of their growth in vitro. Cancer 54: 2959-2967, 1984.

6. O'Farrell PH: High resolution two-dimensional electrophoresis of proteins. J Biol Chem 250: 4007-4021, 1975.

7. Unlu M, Morgan ME and Minden JS: Difference gel electrophoresis: a single gel method for detecting changes in protein extracts. Electrophoresis 18: 2071-2077, 1997.

8. Tonge R, Shaw J, Middleton B, Rowlinson R, Rayner S, Young J, Pognan F, Hawkins E, Currie I and Davison M: Validation and development of fluorescence two-dimensional differential gel electrophoresis proteomics technology. Proteomics 1: 377-396, 2001.

9. Zhou G, Li H, De Camp D, Chen S, Shu H, Gong Y, Flaig M, Gillespie JW, Hu N, Taylor PR, Emmert-Buck MR, Liotta LA, Petricoin EF III and Zhao Y: 2D differential in-gel electrophoresis for the identification of esophageal scans cell cancerspecific protein markers. Mol Cell Proteomics 1: 117-124, 2002.

10. Gharbi S, Gaffney P, Yang A, Zvelebil MJ, Cramer R, Waterfield MD and Timms JF: Evaluation of two-dimensional differential gel electrophoresis for proteomic expression analysis of a model breast cancer cell system. Mol Cell Proteomics 1: 91-98, 2002.

11. Skynner HA, Rosahl TW, Knowles MR, Salim K, Reid L, Cothliff R, McAllister G and Guest PC: Alterations of stress related proteins in genetically altered mice revealed by twodimensional differential in-gel electrophoresis analysis. Proteomics 2: 1018-1025, 2002.

12. Hayashi Y, Yanagawa T, Yoshida H, Yura Y, Nitta T and Sato M: Induction of other differentiation stages in neoplastic epithelial duct and myoepithelial cells from the human salivary gland grown in athymic nude mice. Cancer 55: 2575-2583, 1985.

13. Laemmli UK: Cleavage of structural proteins during the assembly of the head of bacteriophage T4. Nature 15: 680-685, 1970.

14. Futcher B, Latter GI, Monardo P, McLaughlin CS and Garrels JI: A sampling of the yeast proteome. Mol Cell Biol 19: 7357-7368, 1999.

15. Sali A: Functional links between proteins. Nature 402: 25-26, 1999.
16. Oliver S: Guilt-by-association goes global. Nature 403: 601-603, 2000.

17. Knowies MR: Multiplex proteomic analysis by two-dimensional differential in-gel electrophoresis. Proteomics 3: 1162-1171, 2003.

18. Kedes L, Ng SY, Lin CS, Gunning P, Eddy R, Shows T and Leavitt J: The human beta-actin multigene family. Trans Assoc Am Phys 98: 42-46, 1985.

19. Zu YL, Shigesada K, Nishida E, Kubota I, Kohno M, Hanaoka M and Namba Y: 65-kilodalton protein phosphorylated by interleukin 2 stimulation bears two putative actin-binding sites and two calcium-binding sites. Biochemistry 29: 8319-8324, 1990.

20. Hytiroglou P, Choi SW, Theise ND, Chaudhary N, Worman HJ and Yhung SN: The expression of nuclear lamins in human liver: an immunohistochemical study. Hum Pathol 24: 169-172, 1993.

21. Xia D, Li X, Lou Y, Han W, Ding P, Zhang Y, Di C, Song Q and Ma D: Overexpression of chemokine-like factor 2 promotes the proliferation and survival of $\mathrm{C} 2 \mathrm{C} 12$ skeletal muscle cells. Biochim Biophys Acta 1591: 163-173, 2002.

22. Aladib W, Yoshida H and Sato M: Effect of epidermal growth factor on the cellular proliferation and phenotype of a neoplastic human salivary intercalated duct cell line or its derivatives. Cancer Res 50: 7650-7661, 1990.

23. Bosc C, Cronk JD, Pirollet F, Watterson DM, Haiech J, Job D and Margolis RL: Cloning, expression, and properties of the microtubule-stabilizing protein STOP. Proc Natl Acad Sci USA 93: 2125-2130, 1996

24. Vanier MT, Neuville P, Michalik L and Launay JF: Expression of specific tau exons in normal and tumoral pancreatic acinar cells. J Cell Sci 111: 1419-1432, 1998.

25. Hoffman MP, Kibbey MC, Letterio JJ and Kleinman HK: Role of laminin-1 and TGF- 33 in acinar differentiation of a human submandibular gland cell line (HSG). J Cell Sci 109: 2013-2021, 1996.

26. Zheng C, Hoffman MP, McMillan T, Kleinman HK and O'Connell BC: Growth factor regulation of the amylase promoter in a differentiating salivary acinar cell line. J Cell Physiol 177: 628-635, 1998.

27. Jung DW, Hecht D, Ho SW, O'Connell BC, Kleinman HK and Hoffman MP: PKC and ERK $1 / 2$ regulate amylase promoter activity during differentiation of a salivary gland cell line. J Cell Physiol 185: 215-225, 2000. 